\title{
Transport capacity models for unsteady and non-equilibrium sediment transport in alluvial channels
}

\author{
Gokmen Tayfur ${ }^{\text {a }}$, Vijay P. Singh ${ }^{\text {b,c,* }}$ \\ ${ }^{a}$ Dept. Civil Engineering, Izmir Institute of Technology, Urla, Izmir 35340, Turkey \\ ${ }^{\mathrm{b}}$ Dept. Biological and Agricultural Engineering, Texas A and M University, College Station, TX 77843-2117, USA \\ ${ }^{\mathrm{c}}$ Dept. of Civil and Environmental Engineering, Texas A and M University, College Station, TX 77843-2117, USA
}

\section{A R T I C L E I N F O}

\section{Article history:}

Received 28 February 2011

Received in revised form 20 September 2011 Accepted 8 December 2011

\section{Keywords:}

Sediment transport

Non-equilibrium

Unsteady

Transport capacity

Dominant variable

Numerical model

\begin{abstract}
A B S T R A C T
This study investigates transport capacity models based on different dominant variables-shear stress, stream power, unit stream power, flow discharge, flow velocity, and energy slope - in a model of unsteady and non-equilibrium sediment transport in alluvial channels. The model simulates fully coupled system of water flow, suspended sediment, and bed load sediment transport processes in two-layer system of water flow phase and movable bed. The model employs conservation of mass equation for the water in both the layers; suspended sediment in the water flow phase; sediment in the movable bed layer; and the momentum equation for the water flow in the flow phase. The system is closed by relating the sediment flux in the movable bed layer to the sediment concentration in the same layer by employing the kinematic wave theory. Using the sediment transport capacity expression with different dominant variables, a series of numerical experiments are carried out for unsteady and non-equilibrium sediment transport. The results seem theoretically reasonable for hypothetical cases. The model is calibrated and validated using different experimental data sets. The calibrated value for the transport capacity model's exponent $\left(k_{\mathrm{i}}\right)$ is found to be $1.50,1.65,0.24,0.56,4.80$, and 0.22 for shear stress, stream power, unit stream power, discharge, velocity, and slope approaches, respectively. The numerical investigation results show that transport capacity model based on any dominant variable can be employed for modelling unsteady and non-equilibrium sediment transport.
\end{abstract}

(c) 2011 Elsevier B.V. All rights reserved.

\section{Introduction}

Physically-based sediment transport equations have been derived from the assumption that sediment transport capacity can be determined by a dominant variable, such as flow discharge, flow velocity, slope, shear stress, stream power, and unit stream power (Yang, 1996). Yang $(1972,1983)$ used data collected by Guy et al. (1966), who carried out 339 experiments from 1956 to 1961 in a laboratory flume under steady and uniform flow conditions, to test the validity of the transport capacity formulations based on several dominant variables. His analysis showed that more than one value of total sediment discharge can be obtained for the same value of water discharge, velocity, slope and shear stress, implying weak relation between these dominant variables and the total sediment loads. His test results, at the same time, showed that stream power and unit stream power have a stronger correlation with the total sediment load. Yang $(1983,1984)$ extended his analysis to the gravel data of Meyer-Peter and Muller (1948) and verified that

\footnotetext{
* Corresponding author at: Dept. Biological and Agricultural Engineering, Texas A and M University, College Station, TX 77843-2117, USA.

E-mail addresses: gokmentayfur@iyte.edu.tr (G. Tayfur), vsingh@tamu.edu (V.P. Singh),
}

bed load can be more uniquely determined by unit stream power than by shear stress or stream power. In addition, Yang and Molinas (1982) have theoretically shown that bed load is directly related to unit stream power rather than other dominant variables. Hence, Yang $(1984,1996)$ concluded that sediment transport rate or concentration should be related to the rate of energy dissipation approach on which the unit stream power and the stream power models are based. However, in practice the excess shear stress approach is rather commonly employed (Smart, 1984; Hotchkiss and Parker, 1991; Cui et al., 1996; Cui and Parker, 2005; Li and Millar, 2007; Tayfur and Singh, 2007; Papanicolaou et al., 2008, among others). Many investigators believe that shear stress or stream power would be more suitable for the study of bed load movement, because these parameters represent force or power acting on the bed (Yang, 1996; Singh et al., 2004; Wu, 2004; Papanicolaou et al., 2008). Transport capacity based on other dominant variables of discharge, slope, and velocity have also been employed by several investigators (Armanini and di Silvio, 1988; Yang, 1996; Tayfur et al., 2003; Singh et al., 2004; Wu et al., 2004; Bathurst, 2007).

Many studies have investigated steady and equilibrium sediment transport (Papanicolaou et al., 2008). In unsteady and non-equilibrium sediment transport modelling, which has recently received significant attention, shear stress (Tayfur and Singh, 2007), 
stream power (Wu, 2004; Wu et al., 2004; Singh et al., 2004) and energy slope (Singh et al., 2004) approaches have been employed.

The above discussion shows that there is no consensus as to which dominant variable should be employed in transport capacity modelling. There seems no study which has qualitatively investigated transport capacity models based on different dominant variables in the simulation of unsteady and non-equilibrium sediment transport in alluvial channels. This is what motivated this study.

Recently developed physics-based models mostly consider nonequilibrium by employing an additional equation for the lag adaptation length (Mohammadian et al., 2004; Singh et al., 2004). Wu (2004) and Wu et al. (2004) modelled non-equilibrium transport by incorporating the adaptation length equation within the system of the equations. By doing so, in a way, they closed the system where the temporal gradient of bed elevation disappeared from the conservation of bed sediment mass equation. This study, as it is given in the following section, employed the balance equation between flow transport capacity and sediment load in suspension in the general fully coupled system of equations. Depending upon the balance between transport capacity and sediment load in suspension there would be either entrainment from or deposition on the bed layer. Otherwise, the transport would take place at equilibrium. The adaptation length effect is accounted for by its coefficient, as it is known in the literature (Wu, 2004; Wu et al., 2004; Singh et al., 2004). Contrary to most frequently employed diffusion or dynamic approaches where the bed flux is related to flow variables, the system of equations is closed by employing the kinematic wave theory (Langbein and Leopold, 1968) that relates the bed sediment flux to sediment concentration (bed level) in the movable bed layer.

Tayfur and Singh (2007) employed the kinematic wave theory in the modelling of non-equilibrium sediment transport in alluvial streams. However, their study has several shortcomings: (1) they did not calibrate and validate their model with measured data; (2) they used parameter values suggested by Foster (1982) for sheet sediment transport by overland flow in the simulation of laboratory flume data; and (3) they employed the excess shear stress approach and did not test the other dominant variables for the transport capacity model. It seems that there is no study which qualitatively investigated transport capacity modelling based on different dominant variables when modelling non-equilibrium transient sediment wave movement conceptualised as kinematic waves by Langbein and Leopold (1968) in alluvial channels.

The objective of this study therefore is to investigate transport capacity models based on six different dominant variables-shear stress, stream power, unit stream power, discharge, velocity, and slope- in the modelling of unsteady and non-equilibrium sediment waves conceptualised as kinematic waves in alluvial channels.

\section{Mathematical development}

\subsection{General equations}

For a wide rectangular alluvial channel with constant width, employing diffusion wave approximation for water flow momentum and kinematic wave theory for relating movable bed layer sediment rate to the bed sediment concentration, the system of equations for unsteady, and non-equilibrium sediment transport in a two-layer system (Fig. 1) without lateral inflows can be expressed as (Tayfur and Singh, 2007):

$$
\frac{\partial h(1-c)}{\partial t}+\frac{\partial h u(1-c)}{\partial x}+p \frac{\partial z}{\partial t}=0
$$

$\frac{\partial h c}{\partial t}+\frac{\partial h u c}{\partial x}=\frac{1}{\rho_{\mathrm{s}}}\left[E_{\mathrm{z}}-D_{\mathrm{s}}\right]$

$$
\begin{aligned}
& (1-p) \frac{\partial z}{\partial t}+\frac{\partial q_{\mathrm{bs}}}{\partial x}=\frac{1}{\rho_{\mathrm{s}}}\left[D_{\mathrm{s}}-E_{\mathrm{z}}\right] \\
& \left(\frac{\partial h}{\partial x}+\frac{\partial z}{\partial x}\right)=\left(S_{o}-S_{\mathrm{f}}\right) \\
& q_{\mathrm{bs}}=(1-p) v_{\mathrm{s}} z\left[1-\frac{z}{z_{\mathrm{max}}}\right]
\end{aligned}
$$

where $h=$ flow depth $(L) ; u=$ flow velocity $(L / T) ; c=$ volumetric suspended sediment concentration $\left(L^{3} / L^{3}\right) ; p=$ bed sediment porosity $\left(L^{3} / L^{3}\right) ; z=$ mobile bed layer level $(L) ; \rho_{\mathrm{s}}=$ sediment mass density $\left(M / L^{3}\right) ; E_{\mathrm{z}}=$ entrainment rate $\left(M / \mathrm{L}^{2} / T\right) ; D_{\mathrm{s}}=$ deposition rate $\left(M / \mathrm{L}^{2} /\right.$ $T) ; q_{\mathrm{bs}}=$ bed sediment $\left(L^{2} / T\right) ; S_{\mathrm{f}}$ is the friction slope computed by Chezy's approach; $S_{\mathrm{o}}=$ channel bed slope; $v_{\mathrm{s}}=$ velocity of sediment particles as concentration approaches zero $(L / T)$; and $z_{\max }$ is the maximum bed layer level $(L)$.

Eq. (1) is for conservation of mass for water in both the layers of movable bed and flow phase; Eq. (2) is for the conservation of mass for suspended sediment in the water flow phase; Eq. (3) is the conservation of mass for bed sediment in the movable bed layer (Fig. 1); Eq. (4) is the diffusion wave approximation for the momentum equation of water flow in the flow phase, and Eq. (5) is the kinematic wave theory relating sediment flux to sediment concentration [bed level].

Analysing experimental data on sand transport in flumes and pipes, cobble transport in a natural river and bead transport in a flume, Langbein and Leopold (1968) developed the kinematic wave theory for transient sediment waves in natural channels. They proposed a function relating sediment flux to areal sediment concentration $\left(C_{\mathrm{b}}\right)$. Tayfur and Singh (2006), based on the theory of Langbein and Leopold (1968), developed Eq. (5) that relates bed sediment flux to bed level. Tayfur and Singh (2006) tested the kinematic wave theory model against laboratory experiments and hypothetical cases.

The last term on the right hand sides of Eqs. (2) and (3) accounts for the non-equilibrium. When $E_{\mathrm{z}}>D_{\mathrm{s}}$, the sediment fuses into suspension from the bed, otherwise it deposits on the bed. When $E_{z}=D_{s}$ the transport takes place at equilibrium. Therefore, depending upon the balance between these two variables, either sediment is entrained from the bed into suspension or some sediment in suspension deposits on the bed.

Detachment rate $\left[E_{\mathrm{z}}\right]$ can be expressed as (Yang, 1996)

$E_{\mathrm{z}}=\sigma T_{\mathrm{c}}$

where

$T_{\mathrm{c}}=\eta_{\mathrm{i}}\left(D-D_{\mathrm{c}}\right)^{k_{\mathrm{i}}}$

where $T_{\mathrm{c}}$ is the flow transport capacity; $\eta_{\mathrm{i}}$ and $k_{\mathrm{i}}$ are the parameters; $D$ is a dominant variable and $D_{\mathrm{c}}$ is the critical condition of dominant variable at incipient motion $(\mathrm{M} / \mathrm{L} / \mathrm{T}) . \sigma$ is the transfer rate coefficient corresponding to the inverse of the lag adaptation length $\left(L_{\mathrm{ad}}\right)$ [i.e $\left.\sigma=1 / L_{\mathrm{ad}}\right]$ (Wu et al., 2004).

Deposition rate $\left[D_{s}\right]$ can be expressed as (Yang, 1996):

$D_{\mathrm{s}}=\sigma\left[\rho_{\mathrm{s}} h u c\right]$

The adaptation length characterises the distance for sediment to adjust from a non-equilibrium state to an equilibrium state $\mathrm{Wu}$, 2008). $L_{\text {ad }}$ has a wide range in the literature and it is computed differently for transport mode and deposition mode. For transport mode, although significantly different values are adopted for $L_{\mathrm{ad}}$, it is generally related to the dominant bed form length, such as ripples, sand dunes, and alternate bars (Wu et al., 2004; Wu, 2008). Sand dune length can be 5-10 times the flow depth. The length of alternate bars may reach 6.3 times the channel width $(\mathrm{Wu}, 2008)$. At a laboratory flume scale, $L_{\mathrm{ad}}=7.3 \mathrm{~h}$; and at a field scale 


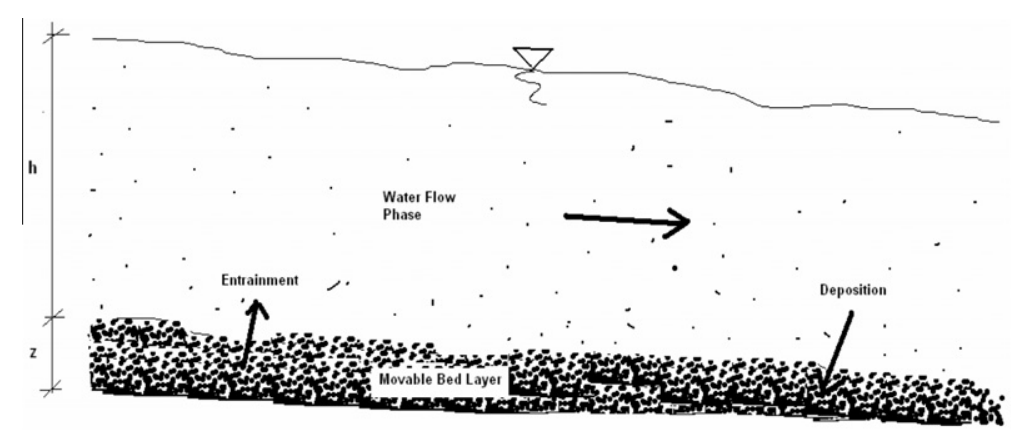

Fig. 1. Schematic Representation for Two-Phase Transport System.

$L_{\mathrm{ad}}=6.3 \mathrm{~W}_{\mathrm{c}}$ [where $W_{\mathrm{c}}$ is channel width] have been suggested by $\mathrm{Wu}$ (2008) and these are employed in this study. For the deposition mode, the adaptation length is computed as $L_{\mathrm{ad}}=q_{\mathrm{w}} \alpha_{\mathrm{c}} V_{\mathrm{f}}$, where $\alpha_{\mathrm{c}}$ is a coefficient; $V_{\mathrm{f}}$ is particle fall velocity; and $q_{\mathrm{w}}$ is the water flow discharge. Although the value of $\alpha_{c}$ varies significantly in the literature (Armanini and di Silvio, 1988; Wu, 2004), Wu et al. (2004) and Wu (2008) suggest $\alpha_{c}=0.5$ which is used in this study. The most recent literature and a-priori sensitivity analysis on this parameter indicate the appropriateness of $\alpha_{c}=0.5$. The particle velocity $\left(v_{\mathrm{s}}\right)$ in Eq. (5) is computed following Bridge and Dominic (1984) and the particle fall velocity which is required in the computation of particle velocity is computed following Dietrich (1982).

\subsection{Transport capacity models}

In the following, we briefly describe the transport capacity model based on different dominant variables. For details, reference is made to Tayfur $(2001,2002)$ and Yang (1996).

\subsubsection{Shear stress approach}

The transport capacity model which is based on excess shear stress can be expressed as:

$T_{\mathrm{c}}=\eta_{\tau}\left(\tau-\tau_{\mathrm{c}}\right)^{k_{\tau}}$

where $\tau=\gamma h S$ is the shear stress $\left(\mathrm{M} / \mathrm{L}^{2}\right) ; \tau_{\mathrm{c}}=\delta_{\mathrm{s}}\left(\gamma_{\mathrm{s}}-\gamma\right) d$ is the critical shear stress $\left(\mathrm{M} / \mathrm{L}^{2}\right) ; \gamma=$ specific weight of water $\left(\mathrm{M} / \mathrm{L}^{3}\right) ; \delta_{\mathrm{s}}=\mathrm{a}$ constant dependent on flow conditions; $\gamma_{\mathrm{s}}=$ specific weight of sediment $\left(\mathrm{M} / \mathrm{L}^{3}\right)$; and $d=$ particle diameter.

\subsubsection{Stream power approach}

Bagnold (1966) was the first one who introduced the stream power concept and defined it as the power per unit area of stream bed. He expressed it as "shear stress $x$ flow velocity", i.e., $\tau u$, where $\tau$ is the shear stress and $u$ is the flow velocity. The transport capacity model which is based on the stream power can then be expressed as (Yang, 1996):

$T_{\mathrm{c}}=\eta_{\tau u}\left(\tau u-\tau_{\mathrm{c}} u_{\mathrm{c}}\right)^{k_{\tau u}}$

where $u_{\mathrm{c}}$ is the critical flow velocity (L/T). $u$ is computed from the flow dynamics part of the model as described by Eq. (4) and critical flow velocity $\left(u_{\mathrm{c}}\right)$, expressed as a function of fall velocity and shear velocity Reynolds number, is computed following Yang (1996).

\subsubsection{Unit stream power approach}

Yang (1972) was the first one who introduced the unit stream power concept. He defined it as the time rate of potential energy dissipation per unit weight of water. He expressed it as "flow velocity times energy gradient", i.e, $u S_{\mathrm{f}}$, where $S_{\mathrm{f}}$ is generally approximated by channel bed slope $(S)$. The transport capacity model based on the unit stream power can then be expressed as (Yang, 1996):

$T_{\mathrm{c}}=\eta_{u s}\left(u S-u_{\mathrm{c}} S_{\mathrm{c}}\right)^{k_{u s}}$

where $S_{\mathrm{c}}$ is the critical slope at incipient sediment motion. By utilising the bed load equation of Meyer-Peter and Muller (1948) the slope at incipient motion $\left(S_{\mathrm{c}}\right)$ can be obtained as:

$S_{\mathrm{c}}=\frac{0.058 d n^{1.5}}{h d_{90}^{0.25}}$

where $d_{90}$ is the bed material size where $90 \%$ is finer $(L)$; and $n$ is Manning roughness coefficient which is related to Chezy roughness, by approximating the hydraulic radius $(R)$ with flow depth $(h)$; as $n=h^{1 / 6} / C_{\mathrm{z}}$. Note that in Eq. (12), $h, d$, and $d_{90}$ are in meter $(\mathrm{m})$.

\subsubsection{Discharge approach}

The discharge approach can be expressed as:

$T_{\mathrm{c}}=\eta_{q}\left(q-q_{\mathrm{c}}\right)^{k_{q}}$

where $q$ is the unit water flow flux $\left(\mathrm{L}^{2} / \mathrm{T}\right)$ computed from the flow part of the model $q=\alpha h \beta$ and $q_{c}$ is the critical unit flow discharge $\left(\mathrm{L}^{2} / \mathrm{T}\right)$, expressed, approximating energy slope by channel bed slope, as follows:

$q_{c}=\frac{0.60 d^{1.5}}{S^{1.167}}$

Eq. (14) is in principle for sediments with specific gravity $2.65 \mathrm{~g} /$ $\mathrm{cm}^{3}$. Note that in Eq. (14) the particle size $d$ is in meter $(\mathrm{m})$.

\subsubsection{Velocity approach}

The velocity approach can be expressed as:

$T_{c}=\eta_{u}\left(u-u_{c}\right)^{k_{u}}$

where, as stated earlier, $u$ is expressed by Eq. (4) and $u_{\mathrm{c}}$ is computed following Yang (1996).

\subsubsection{Slope approach}

The transport capacity model based on slope can be expressed as:

$T_{\mathrm{c}}=\eta_{\mathrm{s}}\left(S-S_{\mathrm{c}}\right)^{k_{\mathrm{S}}}$

where, $S_{\mathrm{c}}$ is expressed by Eq. (12).

The system of equations (Eqs. (1)-(5)) was solved numerically using an explicit method under specified initial $\left[h(x, 0)=h_{0} ; c(x\right.$, $0)=c_{o}$; and $\left.z(x, 0)=z_{o}\right]$ and upstream boundary conditions $[h(0$, $t)=h(t) ; c(0, t)=c(t)$; and $z(0, t)=z(t)]$. As downstream boundary conditions, zero-gradient flow depth, zero-gradient bed level, and zero-gradient suspended sediment concentration were assumed. 


\section{Model evaluation}

\subsection{Evaluation using hypothetical cases}

Before calibrating and validating the model using experimental data, the model was tested with hypothetical cases in order to see whether it would produce plausible results. To that end, the channel was assumed as: $1100 \mathrm{~m}$ length, $20 \mathrm{~m}$ width, 0.0025 bed slope and roughness coefficient $C_{\mathrm{z}}=50 \mathrm{~m}^{0.5} / \mathrm{s}$. The sediment was assumed to have $\rho_{\mathrm{s}}=2650 \mathrm{~kg} / \mathrm{m}^{3}, d_{\mathrm{s}}=0.32 \mathrm{~mm}$ and $p=0.40$. It was assumed that inflow had a trapezoidal shape with $20 \mathrm{~m}^{3} / \mathrm{s}$ base flow rate until 30th min and then it linear increase to $50 \mathrm{~m}^{3} / \mathrm{s}$ at 90th min, staying constant until 120th min and then a linear decrease back to the base flow rate at 180 th min, staying constant onward. A constant suspended sediment concentration (SSC) inflow rate of $c=0.011 \mathrm{~m}^{3} / \mathrm{m}^{3}$ and a constant bed sediment inflow rate of $C_{\mathrm{b}}=47.0 \mathrm{~kg} / \mathrm{m}^{2}$ were assumed.

For this particular hypothetical case, the excess shear stress approach for flow transport capacity was employed. It may be noted that for the transport capacity, any other dominant variable approach, such as stream power, unit stream power, velocity, discharge, and slope, can also be employed. One would obtain similar profile results from the hypothetical numerical experiments presented in Figs. 2-5, with different magnitudes. We employed the same procedure for model performance for the hypothetical case using other dominant variables as well and obtained similar results, as presented in Figs. 2-5. For the sake of brevity, herein we only present the ones based on the shear stress approach.

Due to an increase in flow discharge, it is expected that, there would be entrainment (erosion) from the bed layer, resulting in a decrease in the bed level $(z)$ but an increase in the suspended sediment concentration (SSC) (c). The effect of increase in the transport capacity due to the increase in the flow rate on $z$ and $c$ along a channel length is shown in Fig. 2. As seen, $z$ gradually de-
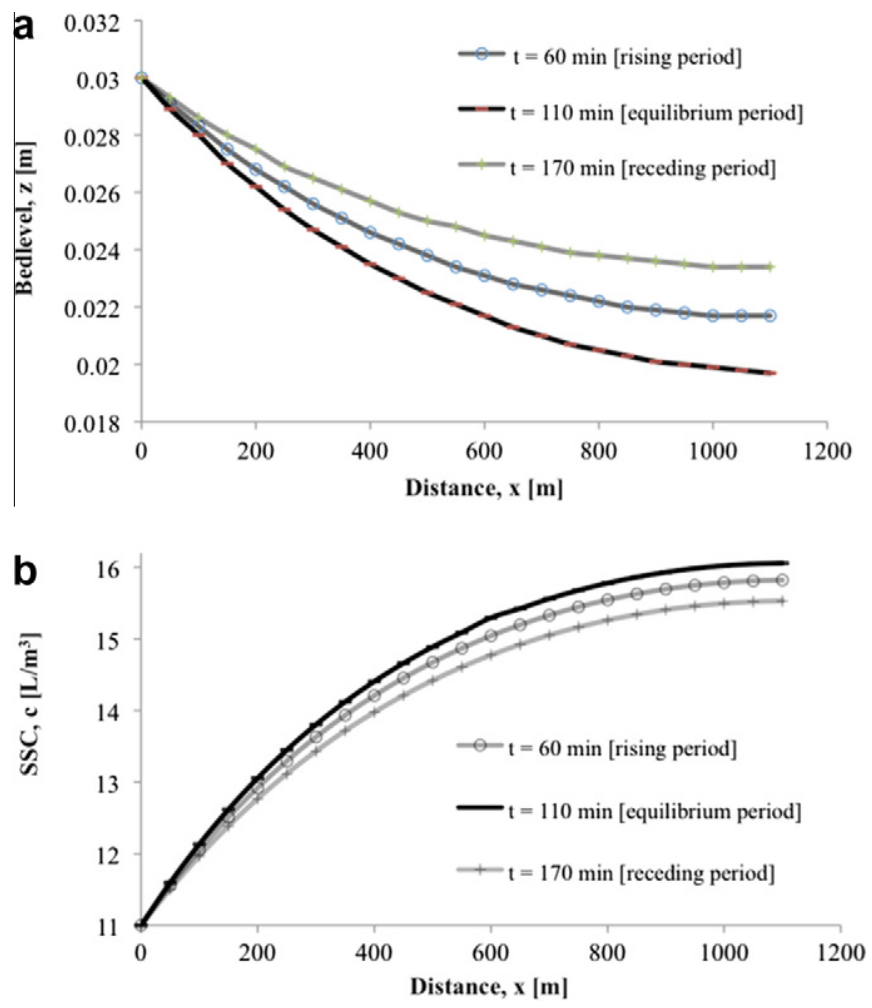

Fig. 2. Spatial variation in (a) $z$; and (b) $c$ during different periods of simulation.
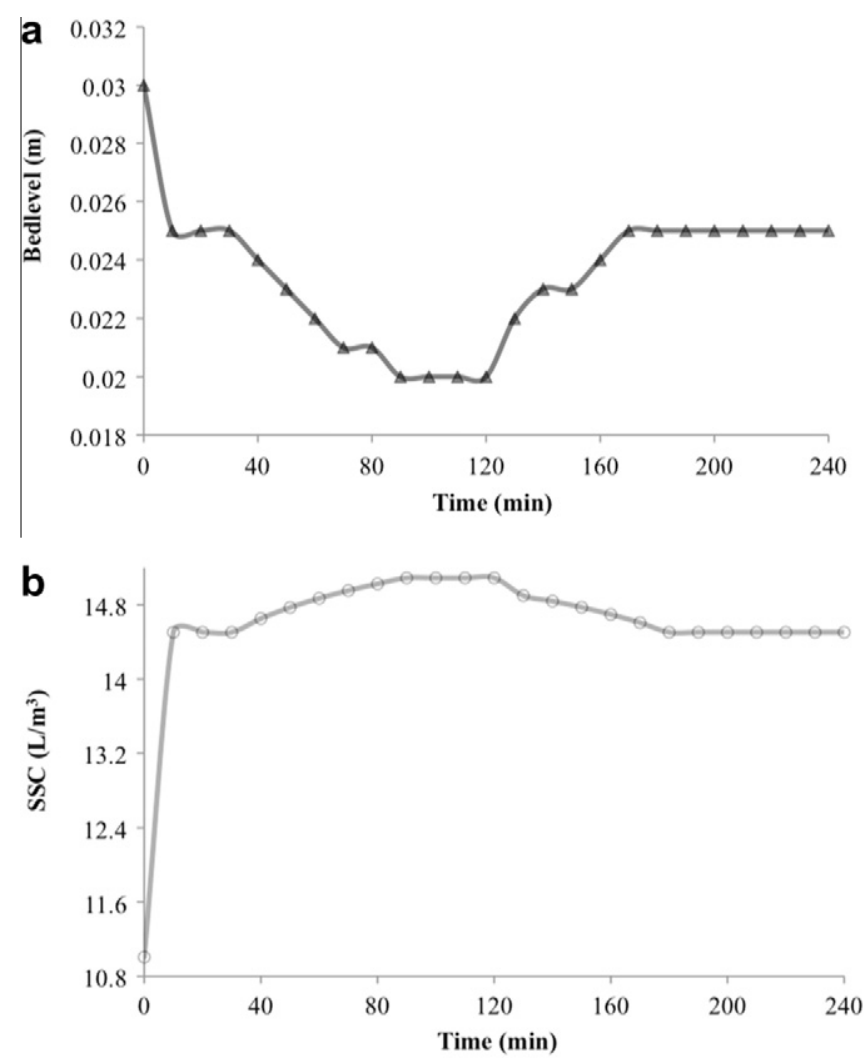

Fig. 3. Temporal variation in (a) $z$; and (b) $c$ at the middle section of the channel.

creases along the channel length during the rising ( $t=60 \mathrm{~min}$ ) and equilibrium periods $(t=110 \mathrm{~min})$ of the flood hydrograph. It then starts increasing during the hydrograph recession $(t=170 \mathrm{~min})$ of (Fig. 2a). The suspended sediment concentration (SSC), on the other hand, shows the opposite behaviour (Fig. 2b). It gradually increases during the hydrograph rise, reaching a maximum value when flow rate is at equilibrium; it then starts gradually decreasing during the hydrograph recession (Fig. 2b). This is because during the rising and equilibrium flood periods the transport capacity of flow increases and consequently entrains material from the bed layer and infuses them into suspension. During the recession period, however, the transport capacity starts decreasing, resulting in the deposition of the material on the bed layer and thus a decrease in suspended sediment in the flow phase.

Fig. 3 shows the temporal variation of $z$ and $c$ at the middle section of the channel where bed level, $z$ decreases/increases while the suspended sediment concentration, $c$ increases/decreases following the increase/decrease in the flow transport capacity. As seen, $z$ has the lowest value when flow rate has its highest value during the equilibrium period of the hydrograph (Fig. 3a). However, $c$ has a maximum value at the same time (Fig. $3 b$ ).

Fig. 4 shows the temporal variation in the middle section of the same channel. The same inflow hydrograph and sedimentographs were employed for this particular hypothetical case. The channel width was varied so as to have different flow depths and flow velocities. The width varied from $W_{\mathrm{c}}=10 \mathrm{~m}$ to $W_{\mathrm{c}}=40 \mathrm{~m}$, resulting in different flow conditions. It is expected that when channel width is increased the flow depth and flow velocity would decrease, resulting in a lower transport capacity and consequently deposition on the channel bed. When the width is decreased, the opposite behaviour would be expected that is higher transport capacity resulting in entrainment from channel bed. As seen in Fig. 4, as the channel width decreases the flow depth and velocity increase, resulting in entrainment due to the increase in the flow transport 


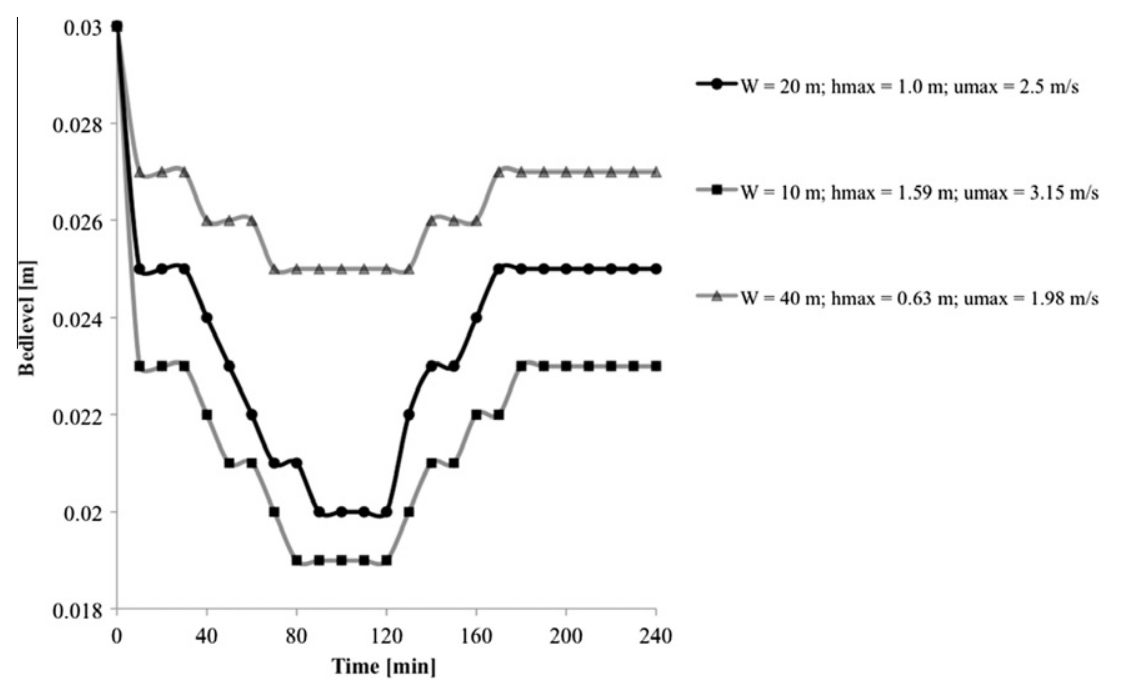

Fig. 4. Temporal variation in bed profile in middle section of channel.
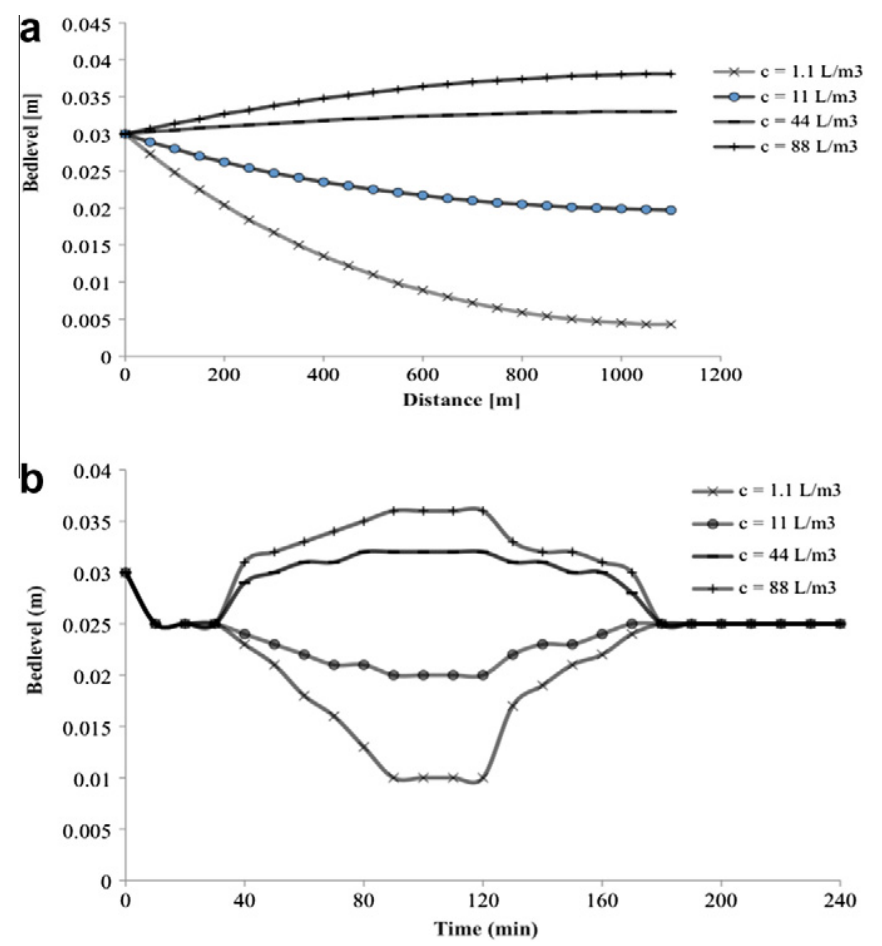

Fig. 5. (a) Spatial variation in bedlevel along the channel length; and (b) temporal variation of bedlevel in the middle section of the channel.

capacity. On the other hand, when channel width is increased, it results in lower flow depth, flow velocity and transport capacity, and consequently a deposition on the channel bed (Fig. 4).

Fig. 5 shows spatial and temporal variation in the channel bed level under different suspended sediment loadings from the upstream end. For this particular hypothetical case, the same channel with the same inflow hydrograph was assumed. The suspended sediment loading was varied at the upstream end of the channel. The suspended sediment loading was linearly decreased from $11 \mathrm{l} / \mathrm{m}^{3}$ to $1.1 \mathrm{l} / \mathrm{m}^{3}$ during the rising period of the hydrograph and then it was linearly increased back to $11 \mathrm{l} / \mathrm{m}^{3}$ during recession period. Similarly, suspended sediment loading was linearly increased from $11 \mathrm{l} / \mathrm{m}^{3}$ to $44 \mathrm{l} / \mathrm{m}^{3}$ during the rising period and then back to the original value during the hydrograph recession. Finally, the suspended sediment loading was linearly increased from $11 \mathrm{l} /$ $\mathrm{m}^{3}$ to $88 \mathrm{l} / \mathrm{m}^{3}$ during the rising period and then back to $11 \mathrm{l} / \mathrm{m}^{3}$ during the hydrograph recession. It is expected that an increase in the loading would result in an increase in the bed level as a result of deposition. A decrease in the loading would result in less suspended sediment in the flow phase and thus strong flow transport capacity eroding from channel bed. As seen in Fig. 5a, the bed level gradually increases/decreases along the channel length as a result of increase/decrease in the suspended sediment inflow. Similarly, temporal variation in the bed level shows that a deficit of suspended load results in entrainment from channel bed or overloading of suspended sediment causes deposition on the channel bed (Fig. 5b).

These results imply that the developed unsteady and non-equilibrium sediment transport model was able to reasonably simulate moving bed profiles and suspended sediment transport in alluvial channels.

\subsection{Model calibration}

The developed model was calibrated using the laboratory flume experimental data of Yen et al. (1992) who carried out aggradation and degradation experiments in a $72.0 \mathrm{~m}$ long and $1.0 \mathrm{~m}$ wide flume which had a 0.0035 bed slope. They kept the water discharge constant at a rate of $0.12 \mathrm{~m}^{3} / \mathrm{s}$. They used sediment of $d_{50}=1.8 \mathrm{~mm}, d_{90}=7.2 \mathrm{~mm}$, and $\rho_{\mathrm{s}}=2650 \mathrm{~kg} / \mathrm{m}^{3}$. At the beginning of the experiment, they continuously released a sediment supply rate of $3.3 \mathrm{~kg} / \mathrm{min}$ (dry mass) from the upstream end until the channel bed reached a steady state of equilibrium. They then increased the sediment supply rate to $9.9 \mathrm{~kg} / \mathrm{min}$ until a new equilibrium was reached. They then reduced the rate of sediment supply back to and kept at $3.3 \mathrm{~kg} / \mathrm{min}$ until another new equilibrium was reached. They measured bed elevations by bed-level gauges at six different locations that were $5 \mathrm{~m}$ apart from each other. They used a sluice gate at the downstream end of the flume to maintain a constant tail-water level. The details of the experiment can be obtained from Yen et al. (1992).

In model simulations, since the water level was around $0.15 \mathrm{~m}$, $z_{\max }=0.10 \mathrm{~m}$ was employed. The bed sediment porosity was assumed to be $p=0.40$. Gessler (1965) suggests 0.047 for $\delta_{\mathrm{s}}$ for most of flow conditions and this was employed in this simulation. Note that since sediment was fed from the upstream end as only bed load, suspended sediment concentration was zero at this end during the experiment. The soil detachability parameter $\left(\eta_{\mathrm{i}}\right)$ has a 
range between 0 and 1 (Yang, 1996; Wu, 2008) and this study employed $\eta_{\mathrm{i}}=0.82$. It may be noted that Foster (1982) suggests $\eta_{\mathrm{i}}=0.60$. Furthermore, as a result of apriori sensitivity analysis of this parameter, we set $\eta_{\mathrm{i}}=0.82$ during the calibration procedure. As pointed out earlier, the transfer rate coefficient $\left[\sigma=1 / L_{\mathrm{ad}}\right]$ was computed differently for the transport mode and the deposition mode, following Wu et al. (2004) and Wu (2008). The only parameter that was calibrated was the exponent $k_{\mathrm{i}}$ for each transport capacity model.

Figs. 6-11 show model simulations of bed levels measured by Yen et al. (1992) at six different locations of the flume. Location \#1 is $9.5 \mathrm{~m}$ away from the upstream end where the sediment supply was located. Locations \#2, \#3, \#4, \#5 and \#6 are 5, 10, 15, 20 and $25 \mathrm{~m}$ away from Location \#1, respectively (Yen et al., 1992). The model simulations of transient bed levels at the specified locations are satisfactory. The model closely predicted bed levels during rising, equilibrium, and recession periods satisfactorily. The computed mean absolute error [MAE] for the simulations in Figs. 6-11 for each transport capacity model is about $M A E=0.58 \mathrm{~cm}$ and the coefficient of determination is $R^{2}=0.964$. The calibrated $k_{\mathrm{i}}$ values for each transport capacity model that resulted in the satisfactory simulations in Figs. 6-11 are presented in Table 1.

\subsection{Model verification}

The calibrated model was then applied to simulate different sets of experimental data collected by Seal et al. (1997). The purpose of this simulation was to validate the developed model. Seal et al. (1997) used a $45 \mathrm{~m}$ long, $1.2 \mathrm{~m}$ deep, and $0.30 \mathrm{~m}$ wide experimental flume. The channel floor had an initial slope of 0.002 . They had constant water discharge of $49 \mathrm{l} / \mathrm{s}$ for the experiment. The tailgate water elevation was kept at $0.45 \mathrm{~m}$. They used sediment mixture comprising a very wide range of sizes ranging from $0.125 \mathrm{~mm}$ to $64 \mathrm{~mm}$, with a median size of $6 \mathrm{~mm}$. This study simulated two data sets-one set from Run \#1 at time $16.4 \mathrm{~h}$ and another set from Run \#2 at time $32.4 \mathrm{~h}$. In the first run the sediment was fed at a constant rate of $11.30 \mathrm{~kg} / \mathrm{min}$ while in the second run this rate was $5.65 \mathrm{~kg} / \mathrm{min}$. They measured bed elevation profiles at 18 locations from about $2.0 \mathrm{~m}$ to $45 \mathrm{~m}$ downstream of the sediment feed point using standard point gauges. Details can be obtained from Seal et al. $(1995,1997)$.

Figs. 12 and 13 show simulations of measured data by the calibrated model for each transport capacity formulation, i.e. the same exponent values in Table 1 are used. As seen in these figures, all the models performed almost equally well in simulating the measured data. The computed $M A E=0.032 \mathrm{~m}$ and $R^{2}=0.982$ for the simulation of Run \#1 experiment at $16.4 \mathrm{~h}$ (Fig. 12). The computed $M A E=0.030 \mathrm{~m}$ and $R^{2}=0.984$ for the Run $\# 2$ experiment at $32.4 \mathrm{~h}$ (Fig. 13). These results imply that the calibrated model is

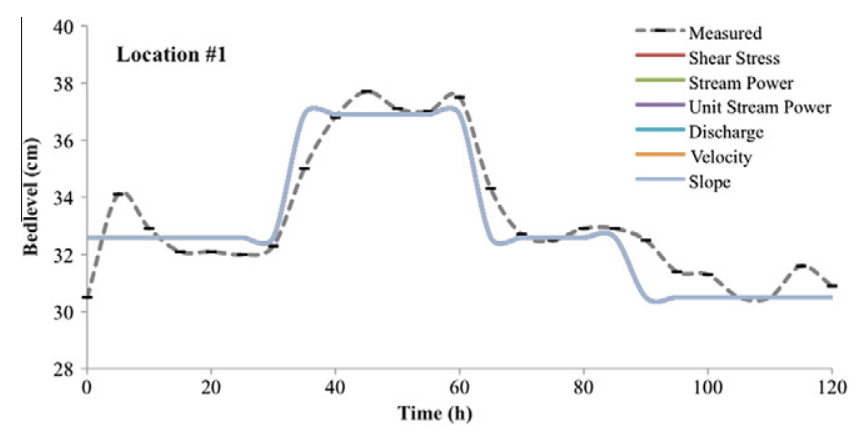

Fig. 6. Simulation of bed profile at Location \#1 [9.5 $\mathrm{m}$ away from the upstream end where sediment supplier was located].

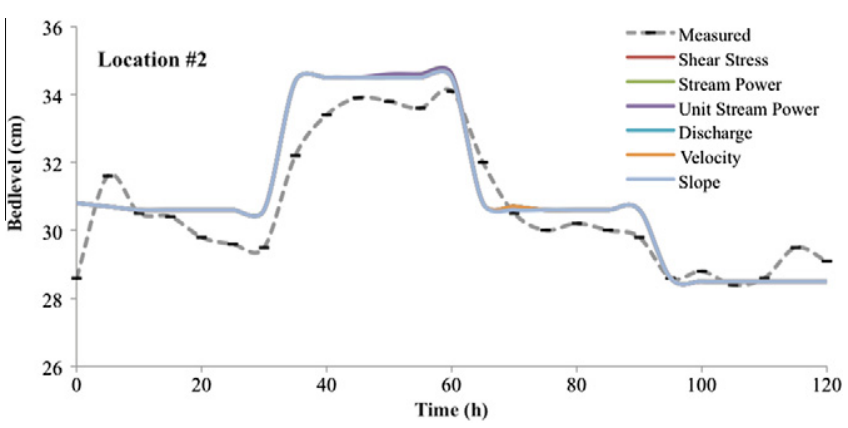

Fig. 7. Simulation of bed profile at Location \#2 [5 $\mathrm{m}$ away from Location \#1].

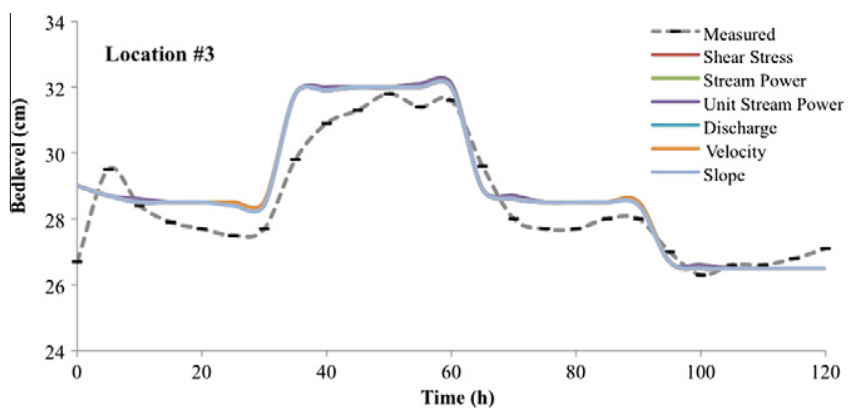

Fig. 8. Simulation of bed profile at Location \#3 [10 $\mathrm{m}$ away from Location \#1].

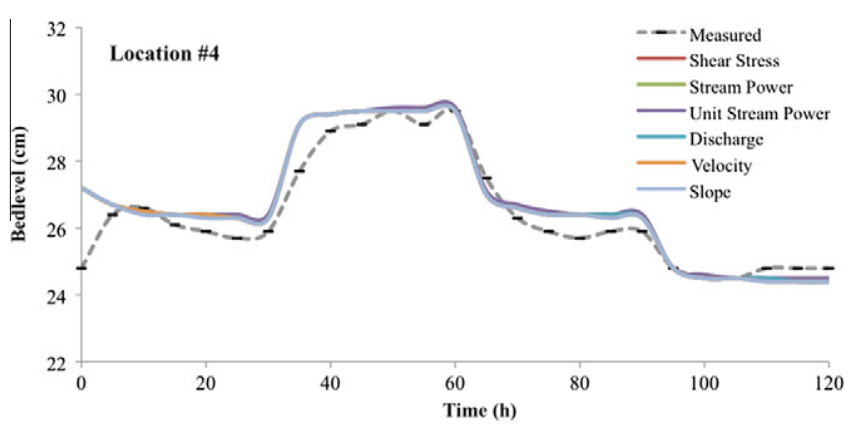

Fig. 9. Simulation of bed profile at Location \#4 [15 $\mathrm{m}$ away from Location \#1].

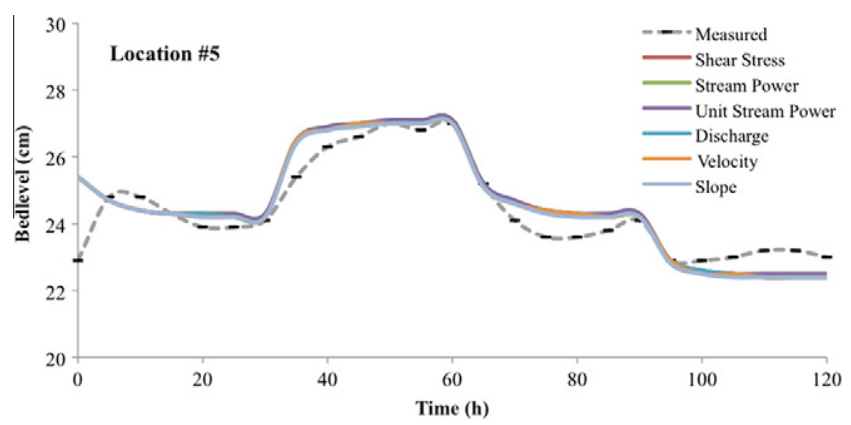

Fig. 10. Simulation of bed profile at Location \#5 [20 m away from Location \#1]

capable of satisfactorily simulating laboratory flume sediment transport experimental runs.

Since the laboratory experiments are generally carried out under controlled uniform flow conditions, as was the case for the data used for the calibration and validation of the developed model, a numerical investigation was carried out to check whether the calibrated models would produce comparable performance when 


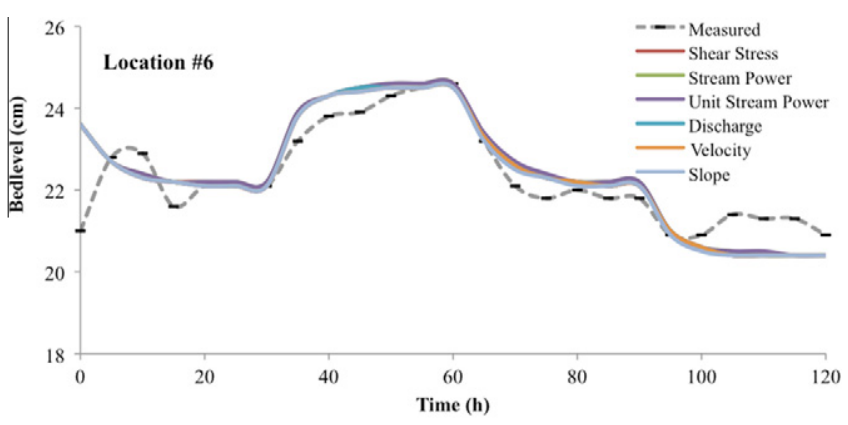

Fig. 11. Simulation of bed profile at Location \#6 [25 $\mathrm{m}$ away from Location \#1].

Table 1

Calibrated $k_{\mathrm{i}}$ values for each transport capacity model.

\begin{tabular}{ll}
\hline Dominant variable & $k_{\mathrm{i}}$ \\
\hline Shear stress & 1.52 \\
Stream power & 1.63 \\
Unit stream power & 0.25 \\
Discharge & 0.58 \\
Velocity & 4.83 \\
Slope & 0.21 \\
\hline
\end{tabular}

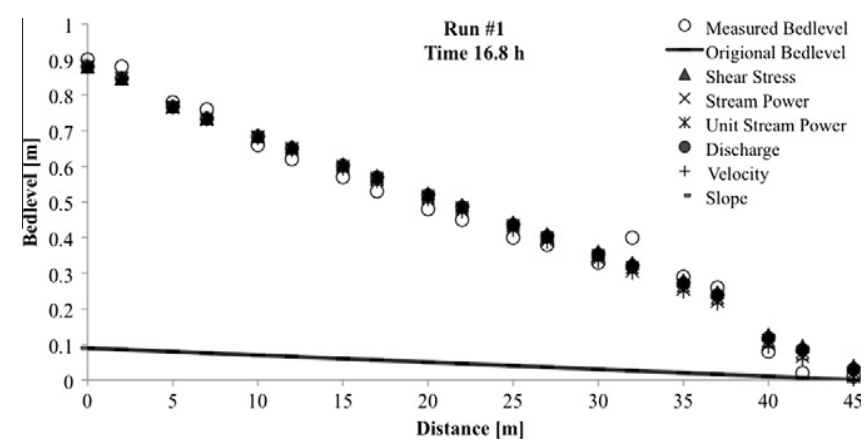

Fig. 12. Simulation of experimental data obtained by Seal et al. (1997) from their Run \#1 experiment at $16.8 \mathrm{~h}$.

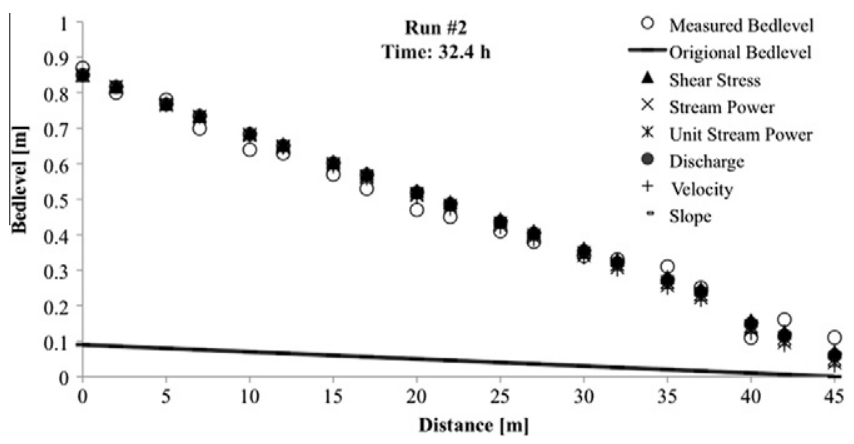

Fig. 13. Simulation of experimental data obtained by Seal et al. (1997) from their Run \#2 experiment at $32.4 \mathrm{~h}$.

applied to a general case where the inflow hydrograph and sedimentographs are unsteady. For this particular purpose, the same channel properties considered in the "Model Testing" section above was assumed. Here, a triangle shape inflow hydrograph having a base flow rate $20 \mathrm{~m}^{3} / \mathrm{s}$ was assumed. It linearly reached a peak rate of $100 \mathrm{~m}^{3} / \mathrm{s}$ at 120 th minute and then decreased linearly back to the base flow rate at the 180th minute. The same triangular shape sedimentograph was assumed for the bed sediment loading at the upstream end with a base load of $C_{\mathrm{b}}=32 \mathrm{~kg} / \mathrm{m}^{2}$ and peak

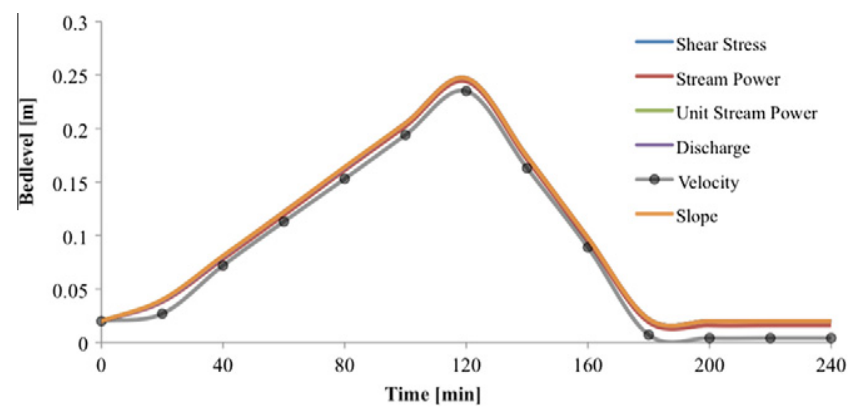

Fig. 14. Temporal variation in bedlevel at 120th min of the simulation period.

load of $C_{\mathrm{b}}=400 \mathrm{~kg} / \mathrm{m}^{2}$. Similarly, the same assumed triangular shape suspended sediment loading from the upstream end involved $5 \mathrm{l} / \mathrm{m}^{3}$ base rate and $50 \mathrm{l} / \mathrm{m}^{3}$ peak rate.

Fig. 14 shows the temporal variation in the middle section of the channel. Note that the same exponent values in Table 1 are used in the corresponding transport capacity models. As seen, all the models showed almost the same performance, with the velocity approach showing an insignificant deviation.

It may be noted that the transport capacity models based on different dominant variables produced the same results as presented in Figs. 6-14. This is because each capacity formulation is producing the same detachment rate with correspondingly different $k_{\mathrm{i}}$ values, as presented in Table 1 .

\section{Concluding remarks}

This study develops a physically-based mathematical model for simulating transient sediment waves under unsteady and nonequilibrium conditions in alluvial streams. It can simulate suspended and as well as bed load rates in time and in space. The model simulates non-equilibrium process through the balance between flow transport capacity and suspended load in the water flow phase. Depending upon the magnitude, the flow either entrains sediment or deposits sediment. The transport capacity model is formulated based on six different dominant variables-shear stress, stream power, unit stream power, discharge, velocity, and slope. The transfer rate coefficient $(\sigma)$ corresponding to the inverse of the lag adaptation coefficient is computed as $\sigma=1 / 7 \mathrm{~h}$ during transport mode and $\sigma=\alpha_{\mathrm{c}} V_{\mathrm{f}} / q_{\mathrm{w}}$ during deposition. The parameter $\left(k_{\mathrm{i}}\right)$ is calibrated for each transport capacity model by simulating measured laboratory experiment. The bed layer sediment flux is related to the bed sediment concentration using the kinematic wave theory.

The model simulation of hypothetical cases produces results that are compatible with those that can be observed in the field. The calibrated model successfully simulates laboratory measured data. These results imply that the developed model is capable of simulating transient sediment waves under non-equilibrium conditions. It is interesting to note that once the exponent parameter in Eq. (7) is calibrated for the corresponding dominant variable approach, the transport capacity model based on any dominant variable can produce reasonably satisfactory simulations.

For general field case applications, the develop model should be re-calibrated and re-validated with measured field data since the values given in Table 1 are obtained from simulating laboratory experimental data under steady flow conditions.

\section{Acknowledgments}

This research was supported by the TUBITAK [Turkish Science and Technical Research Council] under the Grant Number 
106M274. The writers would like to express their sincere appreciation to TUBITAK.

\section{References}

Armanini, A., di Silvio, G., 1988. A one-dimensional model for the transport of a sediment mixture in non-equilibrium conditions. J. Hydraul. Res. 26 (3), 274 292.

Bathurst, J.C., 2007. Effect of course surface layer on bed-load transport. J. Hydraul. Eng. 133 (11), 1192-1205.

Bagnold, R.A., 1966. An approach to the sediment transport problem from general physics. U.S. Geol. Surv. Prof. Pap. 422-J.

Bridge, J.S., Dominic, D.F., 1984. Bed load grain velocities and sediment transport rates. Water Resour. Res. 20 (4), 476-490.

Cui, Y., Parker, G., Paola, C., 1996. Numerical simulation of aggradation and downstream fining. J. Hydraul. Res. 34 (2), 184-204.

Cui, Y., Parker, G., 2005. Numerical model of sediment pulses and sediment supply disturbances in mountain rivers. J. Hydraul. Eng. 131 (8), 646-656.

Dietrich, W.E., 1982. Settling velocity of natural particles. Water Resour. Res. 18 (6) 1615-1626.

Foster, G.R., 1982. Modelling the erosion process. In: Haan, C.T., Johnson, H.P., Brakensiek, D.L. (Eds.), Hydrologic Modelling of Small Watersheds. ASAE, pp. 295-380.

Gessler, J., 1965. The beginning of bedload movement of mixtures investigated as natural armouring in channels. W.M. Keck Lab. Hydraulic and Water Resources, California Institute of Technology, Pasadena California.

Guy, H.P., Simons, D.B., Richardson, E.V., 1966. Summary of alluvial channel data from flume experiments, 1956-1961. U.S. Geol. Surv. Prof. Pap. 462-I, 96p.

Hotchkiss, R.H., Parker, G., 1991. Shock fitting of aggradational profiles due to backwater. J. Hydraul. Eng. 117 (9), 1129-1144.

Langbein, W.B., Leopold, L.B., 1968. River channel bars and dunes-theory of kinematic waves. U.S. Geol. Surv. Prof. Pap. 422-L, 20p.

Li, S.S., Millar, R.G., 2007. Simulating bed-load transport in a complex gravel-bed river. J. Hydraul. Eng. 133 (3), 323-328.

Meyer-Peter, E., Muller, R., 1948. Formula for bed-load transport. In: Proc. Second International Assoc. for Hydraulic Res., Stockholm.

Mohammadian, A., Tajrishi, M., Azad, F.L., 2004. Two-dimenrsional numerica simulation of flow and geo-morphological processes near headlands by using unstructured grid. Int. J. Sediment Res. 19 (4), 258-277.

Papanicolaou, A.N., Elhakeem, M., Krallis, G., Prakash, S., Edinger, J., 2008. Sediment transport modelling review-current and future developments. J. Hydraul. Eng., ASCE 134 (1), 1-14.
Seal, R., Parker, G., Paola, C., Mullenbach, B., 1995. Laboratory Experiments on Downstream Fining of Gravel, Narrow Channel Runs 1 Through 3: Supplemental Methods and Data. St. Anthony Falls Hydraulic Laboratory. University of Minnesota, Minneapolis, MN.

Seal, R., Paola, C., Parker, G., Southard, J.B., Wilcock, P.R., 1997. Experiments on downstream fining of gravel: I. Narrow-channel runs. J. Hydraul. Eng. 123 (10), 874-884.

Singh, A.K., Kothyari, U.C., Raju, K.G.R., 2004. Rapidly varying transient flows in alluvial rivers. J. Hydraul. Res. 42 (5), 473-486.

Smart, G.M., 1984. Sediment transport formula for steep channels. J. Hydraul. Eng. 110 (3), 267-276

Tayfur, G., 2001. Modeling two dimensional erosion process over infiltrating surfaces. J. Hydrol. Engng, ASCE 6 (3), 259-262.

Tayfur, G., 2002. Applicability of sediment transport capacity models for non-steady state erosion from steep slopes. J. Hydrol. Engng, ASCE 7 (3), 252-259.

Tayfur, G., Ozdemir, S., Singh, V.P., 2003. Fuzzy logic algorithm for runoff-induced sediment transport from bare soil surfaces. Adv. Wat. Res. 26, 1249-1256.

Tayfur, G., Singh, V.P., 2006. Kinematic wave model of bed profiles in alluvial channels. Water Resour. Res. 42 (6), W06414.

Tayfur, G., Singh, V.P., 2007. Kinematic wave model for transient bed profiles in alluvial channels under non-equilibrium conditions. Water Resour. Res. 43, W12412. doi:10.1029/2006WR005681.

Wu, W., 2004. Depth-averaged two-dimensional numerical modelling of unsteady flow and nonuniform sediment transport in open channels. J. Hydraul. Eng. 130 (10), 1013-1024.

Wu, W., Vierira, D.A., Wang, S.S.Y., 2004. One-dimensional numerical model for nonuniform sediment transport under unsteady flows in channel networks. J. Hydraul. Eng., ASCE 130 (9), 914-923.

Wu, W., 2008. Computational River Dynamics. Taylor \& Francis, London, UK, 494 pages..

Yang, C.T., 1972. Unit stream power and sediment transport. J. Hydraul. Div., ASCE 98 (10), 1805-1826.

Yang, C.T., Molinas, A., 1982. Sediment transport and unit stream power function. J. Hydraul. Div., ASCE 108 (6), 776-793.

Yang, C.T., 1983. Rate of energy dissipation and river sedimentation. In: Proc. Second International Symposium on River Sedimentation. Nanjing, China.

Yang, C.T., 1984. Unit stream power equation for gravel. J. Hydraul. Eng. 110 (12).

Yang, C.T., 1996. Sediment Transport Theory and Practice. McGraw-Hill, New York, USA.

Yen, C.-L., Chang, S.-Y., Lee, H.-Y., 1992. Aggradation-degradation process in alluvial channels. J. Hydraul. Eng., ASCE 118 (12), 1651-1669. 